\title{
Fundamentos do programa GD Arroz, versões Web e Aplicativo, e seu uso no manejo do arroz irrigado
}

\author{
Silvio Steinmetz ${ }^{1\left(^{*}\right)}$, Santiago Vianna Cuadra ${ }^{1}$, Cristóvão Basilio Pereira $^{1}$, Emerson Langie dos Santos ${ }^{1}$ e \\ Ivan Rodrigues de Almeida ${ }^{1}$ \\ ${ }^{1}$ Embrapa Clima Temperado, Rodovia BR 392, km 78, Caixa Postal 403, CEP 96.010-971 Pelotas, RS. E-mails: silvio.steinmetz@embrapa.br, \\ santiago.cuadra@embrapa.br, cristovao.pereira@embrapa.br, emerson.langie@embrapa.br e ivan.almeida@embrapa.br \\ ${ }^{(*)}$ Autor para correspondência.
}

\section{INFORMAÇÕES}

\section{História do artigo:}

Recebido em 20 de maio de 2018

Aceito em 20 de dezembro de 2018

\section{Termos para indexação:}

Oryza sativa L.

graus-dia

fenologia

manejo da cultura

\section{RESUMO}

A produtividade média de grãos do arroz irrigado no Rio Grande do Sul (RS), responsável por $70 \%$ da produção brasileira de arroz, é relativamente elevada $\left(7,6 \mathrm{tha}^{-1}\right)$. Acredita-se que essa produtividade poderia ser ainda maior se mais produtores fizessem o manejo de acordo com os estádios de desenvolvimento da planta, conforme recomendações técnicas da cultura. O problema é que a ocorrência desses estádios, especialmente o de diferenciação da panícula, é muito variável por ser dependente da temperatura. Por isso, é preferível expressar esses estádios em dias após a emergência, porém estimados por meio de graus-dia (GD) ao invés do número de dias do calendário. Por essa razão foi desenvolvido e validado o programa GD Arroz, disponível nas versões Web e Aplicativo para a plataforma Android. Esse programa permite estimar a data de ocorrência de seis estádios de desenvolvimento da planta, para seis subgrupos de cultivares, em 17 localidades do RS, usando séries históricas (30 anos) de temperatura média diária do ar (Tm) bem como a Tm da safra da cultura. 0 objetivo deste trabalho foi caracterizar os fundamentos do programa GD Arroz e como ele pode ser usado para otimizar a época de realização de algumas práticas de manejo do arroz irrigado no RS. Conclui-se que o programa GD Arroz é uma ferramenta que pode auxiliar os produtores a realizar as práticas de manejo nas épocas mais apropriadas por estimar a data de ocorrência de seis estádios de desenvolvimento da planta.

(c) 2018 SBAgro. Todos os direitos reservados.

\section{Introdução}

O Estado do Rio Grande do Sul é o maior produtor de arroz irrigado do Brasil, tendo contribuído, nas safras 2016/2017 e 2017/2018, com 70\% da produção nacional (Conab, 2018). Embora a produtividade média de grãos seja relativamente alta $\left(7,6 t \mathrm{ha}^{-1}\right)$, acredita-se que essa possa ser ainda maior se forem melhorados alguns aspectos rela- cionados com o manejo da cultura. Além da produtividade, também devem ser considerados os fatores relacionados com a sustentabilidade da lavoura. Para isso, é importante realizar as práticas de manejo na época mais apropriada, considerando a data de ocorrência dos distintos estádios de desenvolvimento da planta (Sosbai, 2016).

Dentre esses estádios, destacam-se o de quatro folhas (V4) - primeira adubação nitrogenada em cobertura e en- 
trada definitiva da água de irrigação; de diferenciação da panícula (R1) - segunda adubação nitrogenada em cobertura; de emissão da folha bandeira ou emborrachamento (R2) ao início de floração (R4) - elevação do nível da água para diminuir o efeito do frio e aplicação de fungicida para controle de brusone (Pyricularia grisea (Cooke) Sacc); de início de maturação (R8) - indicativo de aproximação da colheita, e de maturação completa (R9) - indicativo da época de colheita, que pode ser feita nesse estádio ou um pouco antes (Counce et al., 2000; Sosbai, 2016).

O problema é que a ocorrência desses estádios, especialmente o de diferenciação da panícula (DP ou R1), é muito variável por ser dependente da temperatura (Stansel, 1975; Wilson Jr. et al., 2015). Por isso, é preferível expressar-se o estádio R1 e os demais estádios de desenvolvimento da planta em dias, porém estimados por meio de graus-dia (GD) ou soma térmica, ao invés do número de dias do calendário (Streck et al., 2006; Steinmetz et al., 2013b; 2014). Wilson Jr. et al. (2015) descrevem o uso de um programa denominado "DD50", baseado em graus-dia, para decidir o momento mais apropriado para realizar diversas práticas de manejo na lavoura de arroz irrigado, no Estado de Arkansas, nos Estados Unidos da América do Norte (EUA), de acordo com os estádios de desenvolvimento da planta.

Utilizando o método de graus-dia, Steinmetz et al. (2013a) estimaram a data de ocorrência dos principais estádios de desenvolvimento da planta de arroz, para seis subgrupos de cultivares, em 17 localidades do Rio Grande do Sul (RS), usando séries históricas (30 anos) de temperatura média diária do ar $(\mathrm{Tm})$ e, posteriormente, validaram essas informações para o estádio R1, com dados obtidos em condições de lavoura no RS (Steinmetz et al., 2013b), e para os demais estádios, com informações de três locais com características contrastantes de Tm (Steinmetz et al., 2015b).

A estimativa da data de ocorrência de um determinado estádio de desenvolvimento da planta utilizando séries históricas de Tm é importante, pois indica, em termos médios, a data provável em que o estádio deverá ocorrer. Entretanto, para que essa estimativa seja mais precisa, é importante considerar, também, os valores diários de Tm do ano da safra. Por essa razão, o programa (software) GD Arroz foi desenvolvido visando estimar a data de ocorrência de seis importantes estádios de desenvolvimento da planta em função não apenas dos dados históricos de Tm, mas também como essas estimativas são afetadas pela Tm do ano da safra corrente (Steinmetz et al., 2015a). Dessa forma, pode-se realizar determinada prática de manejo na época mais apropriada. Também é importante que o programa seja acessível via internet para que o produtor, ou o agente de assistência técnica que orienta os produtores, possa acompanhar a evolução dessas estimativas em função das características da(s) sua(s) lavoura(s), tais como, lo- calização, data(s) de emergência e cultivar(es) utilizada(s).

Em função do exposto, o objetivo deste trabalho foi caracterizar os fundamentos do programa GD Arroz (disponível nas versões Web e Aplicativo para a plataforma Android) para estimar a data de ocorrência de seis importantes estádios de desenvolvimento da planta de arroz e como ele pode ser usado para otimizar a época de realização de algumas práticas de manejo do arroz irrigado no Estado do Rio Grande do Sul.

\section{Material e métodos}

Os fundamentos do programa serão descritos a seguir. Para o cálculo de graus-dia utilizou-se a equação:

$$
\mathrm{GD}=\sum_{i=1}^{\mathrm{n}}(\mathrm{Tm}-\mathrm{Tb})
$$

em que: GD $\left({ }^{\circ} \mathrm{C}\right.$ dia) representa o somatório da diferença entre a temperatura média diária do ar (Tm) e a temperatura base (Tb) de $11^{\circ} \mathrm{C}$ (Infeld et al., 1998), da emergência (i=1) a cada um dos seis estádios (n), correspondendo aos graus-dia acumulados para atingir esses estádios. A Tm foi obtida pela média aritmética entre as temperaturas máxima (Tx) e mínima (Tn). Para calcular a Tm foram aplicados os limites de $34{ }^{\circ} \mathrm{C}$ e de $21^{\circ} \mathrm{C}$ (Slaton et al., 1996), respectivamente, para as Tx e Tn, ou seja, valores superiores a estes foram desconsiderados.

Essa equação é também utilizada para o cálculo de graus-dia pelo programa "DD50", sendo considerada uma modificação do conceito original de graus-dia visando estimar o desenvolvimento da planta (GDD), pelo fato de estabelecer limites para os valores diários de Tx e Tn. Isso indica que valores superiores a esses limites não farão com que as plantas se desenvolvam mais rapidamente (Slaton et al., 1996; Wilson Jr. et al., 2015). Essa equação corresponde ao cálculo pelo método residual ou soma de temperaturas efetivas para os casos em que a temperatura-base inferior (Tb) é menor do que a temperatura mínima do ar (Tn) e que a tempertura máxima do ar (Tx) é menor do que a temperatura-base superior $\left(\mathrm{T}_{\mathrm{B}}\right)$, podendo-se assumir os seus resultados como equivalentes ao número de graus-dia acumulados (Villa Nova et al., 1972; Bergamaschi, 2017).

Foram utilizados dados diários de temperatura máxima e mínima do ar de 17 estações meteorológicas convencionais situadas nas regiões produtores de arroz irrigado do Rio Grande do Sul, sendo utilizado o período de 30 anos (1976-2005) para a maioria das estações, como indicado em Steinmetz et al. (2010). Os dados foram obtidos junto ao $8^{\circ}$ Distrito de Meteorologia/Instituto Nacional de Meteorologia ( $8^{\circ}$ Disme/Inmet) e à extinta Fundação Estadual de Pesquisa Agropecuária (Fepagro). 
Tabela 1. Graus-dia ( ${ }^{\circ} \mathrm{C}$ dia) da emergência aos principais estádios de desenvolvimento de sete subgrupos de cultivares de arroz irrigado, durante quatro safras agrícolas.

\begin{tabular}{|c|c|c|c|c|c|c|}
\hline \multirow[b]{2}{*}{ Subgrupo } & \multicolumn{6}{|c|}{ Graus-dia ( ${ }^{\circ} \mathrm{C}$ dia) da emergência ao estádio } \\
\hline & V4 & $\mathbf{R 1}$ & $\mathbf{R 2}$ & R4 & $\mathbf{R} 8$ & $\mathbf{R 9}$ \\
\hline \multicolumn{7}{|c|}{ Muito Precoce 1 (MP1) } \\
\hline (<100 dias) & 162 & 459 & 664 & 802 & 1016 & 1091 \\
\hline \multicolumn{7}{|c|}{ Muito Precoce 2 (MP2) } \\
\hline (100 - 105 dias) & 197 & 512 & 736 & 893 & 1129 & 1210 \\
\hline \multicolumn{7}{|l|}{ Precoce $1(\mathrm{P} 1)$} \\
\hline (106-110 dias) & 195 & 627 & 852 & 1020 & 1240 & 1324 \\
\hline \multicolumn{7}{|l|}{ Precoce 2 (P2) } \\
\hline$(111-120$ dias $)$ & 168 & 673 & 920 & 1091 & 1319 & 1422 \\
\hline \multicolumn{7}{|l|}{ Médio 1 (M1) } \\
\hline (121 - 130 dias) & 179 & 718 & 964 & 1121 & 1345 & 1444 \\
\hline \multicolumn{7}{|l|}{ Médio 2 (M2) } \\
\hline (131 - 135 dias) & 188 & 735 & 986 & 1146 & 1381 & 1446 \\
\hline \multicolumn{7}{|l|}{ Tardio (T) } \\
\hline (136 - 150 dias) & 243 & 937 & 1247 & 1404 & 1657 & 1709 \\
\hline
\end{tabular}

(Fonte: adaptado de STEINMETZ et al., 2009; 2014).

Cultivares/Subgrupos: MP1: IRGA 421(95); MP2: BRS Atalanta(100); BRS Ligeirinho; P1: BRS 6 “Chuí”(110); BRS Querência(110); Epagri 106 (106) P2: BRS Pampa (118); BRS Firmeza(120)*; BR-IRGA 414 (115); IRGA 417(115); IRGA 422 CL* (120); IRGA 423 (120); Inov (CL) (120); Avaxi (CL) (120) Puitá Inta CL (120); M1: BRS Pelota (125); BRS Sinuelo CL (130); BRSCIRAD 302 (128); BR-IRGA 409 (126); BR-IRGA 410(123); Arize QM 1003 (125); Arize QM 1010 (135); Guri Inta CL (125); M2: BRS Fronteira(135); BRS 7 “Taim”(130); BRS Bojuru(135); IRGA 424 (132); SCS 115 CL (135); El Paso L. 144; T: SSCS BRS Tio Taka (141); Epagri 108 (142); Epagri 109 (142); SCS 112 (138); SCS 114 Andosan (140); SCS 116 Satoru (144); SCS 117 CL (144).

*Reenquadradas como P2 por Steinmetz et al. (2014).

Obs.: 1) Os valores entre parênteses referem-se à duração média do ciclo, de acordo com SOSBAI (2014); 2) As cultivares sublinhadas não dispõem de informações de graus-dia e foram incorporadas nos subgrupos de acordo com o grupo de maturação indicado na recomendações técnicas da SOSBAI (2012); 3) Estádios: V4: planta com 4 folhas; R1: diferenciação da panícula; R2: formação do colar da folha bandeira; R4: antese (uma ou mais espiguetas); R8: maturidade de um grão isolado; R9: maturidade completa dos grãos da panícula.

O programa GD Arroz utilizou as mesmas séries históricas de dados de temperatura do ar e os mesmos parâmetros, critérios e subgrupos de cultivares utilizados por Steinmetz et al. (2013a), mas incorporando o subgrupo 7, envolvendo as cultivares de ciclo tardio. Entretanto, ao invés do VBA (Visual Basic for Applications), usado dentro da planilha Excel, as equações foram escritas em um programa numérico, na linguagem FORTRAN, possibilitando a computação automática do número de dias transcorridos entre a emergência e cada um dos seis estádios, assim como a correspondente data de ocorrência do referido estádio.

O programa considera como informações de entrada a série histórica (30 anos) das temperaturas máximas e mínimas diárias do ar, assim como as temperaturas da safra do ano corrente, como descrito a seguir. As exigências em graus-dia para atingir cada um dos seis estádios de desenvolvimento da planta estão indicadas na Tabela 1.

Aos dados obtidos, relativos à duração dos subperíodos desde a emergência até cada um dos seis estádios para a série histórica (30 anos), aplicaram-se equações de regressão linear geradas no processo de validação do método de graus-dia (Steinmetz et al., 2015b), exceto para o estádio R1, em que foram usadas as equações descritas em Steinmetz et al. (2014).
Os dados relativos ao ano da safra também foram calculados, para cada um dos sete subgrupos de cultivares, usando-se os valores médios de graus-dia acumulados dos subgrupos indicados na Tabela 1. Entretanto, neste caso, utilizaram-se os dados diários de Tm obtidos à partir dos dados horários de temperatura (instantânea) repassados pelo Instituto Nacional de Meteorologia (INMET). Da mesma forma que para os dados históricos, a Tm foi calculada pela média entre as temperaturas máxima e mínima em 24 horas.

Os valores do número de dias da emergência até cada um dos seis estádios e a respectiva data de ocorrência desses estádios, no ano da safra, assim como do desvio (dias) entre os períodos calculados com a Tm diária do ano da safra e a Tm diária de 30 anos, são atualizados diariamente através da computação automática pelo programa, em função dos dados recebidos das estações automáticas do Inmet. O programa recalcula diariamente os referidos valores, em função dos dados recebidos, que substituem os dados históricos, conforme a data corrente. O número de dias em que a temperatura média diária do ano corrente é utilizada varia de zero, quando a data da consulta é anterior ou igual à data da emergência selecionada (i.e, ainda não há observações para a safra corrente), ao número to- 
tal de dias entre a emergência e cada um dos seis estádios, quão mais próxima a consulta for feita da data prevista de ocorrência do referido estádio. Finalmente, o programa atualiza automaticamente os valores armazenados no banco de dados que alimenta a página Web.

Para utilizar o programa, na versão Web, que foi lançado em agosto de 2015, deve-se acessar a página do Laboratório de Agrometeorologia da Embrapa Clima Temperado, no seguinte endereço: http://agromet.cpact.embrapa.br e selecionar "Graus-dia (Arroz)". O aplicativo, para Android, que foi lançado em agosto de 2016, pode ser baixado pelo Google Play.

\section{Informações de entrada do programa}

Após entrar no programa, selecionam-se os campos relacionados com a localidade, com a cultivar de interesse e o subgrupo a que ela pertence, e com a data de emergência da lavoura, como descrito a seguir.

\section{Localidade}

Deve-se selecionar uma das 17 localidades: Alegrete; Bagé; Cachoeirinha; Capão do Leão (Pelotas); Eldorado do Sul (Guaíba); Encruzilhada do Sul; Maquiné (Osório); Quaraí; Rio Grande; Santa Maria; Santana do Livramento; Santa Vitória do Palmar; São Borja; São Gabriel; Taquari; Torres ou Uruguaiana.

Caso a localidade desejada não seja uma das 17, seleciona-se a que for mais próxima, ou a que, pela experiência do usuário, apresente características de temperatura do ar semelhantes. As 17 localidades indicadas são as que dispunham de séries longas de dados diários de temperatura média do ar (Tm) sendo que, para a maioria delas, foram usadas séries de 30 anos (1976-2005).

\section{Subgrupo}

O passo seguinte consiste em selecionar um dos sete subgrupos de duração do ciclo biológico, no qual se enquadra a cultivar a ser utilizada. A partir dos ciclos das cultivares (da emergência à maturação), classificados em quatro grupos pela Sosbai (2016), foram estabelecidos sete subgrupos: 1-Muito Precoce 1 (MP1) (<100 dias); 2-Muito Precoce 2 (MP2) (100-105 dias); 3-Precoce 1 (P1) (106-110 dias); 4-Precoce 2 (P2) (111-120 dias); 5-Médio 1 (M1) (121130 dias); 6-Médio 2 (M2) (131-135 dias); 7-Tardio (T) (136150 dias). A subdivisão dos três primeiros grupos em seis subgrupos permitiu agrupar as cultivares em menores faixas de ciclo. Isso foi feito para melhorar a eficácia das estimativas para cada subgrupo e, consequentemente, para as cultivares que fazem parte do mesmo.

\section{Cultivar}

A seguir, seleciona-se a cultivar a ser utilizada. Na fase inicial do programa GD Arroz, as 36 cultivares incluídas nos sete subgrupos eram aquelas indicadas na Tabela $1 . \mathrm{Na}$ última versão do programa constam 51 cultivares, sendo que para 42 delas as exigências térmicas foram determinadas experimentalmente. As nove restantes, que estão sublinhadas, foram incluídas nos subgrupos em função do comprimento do ciclo indicado em Sosbai (2016). As cultivares pertencentes a cada subgrupo são as seguintes: Muito Precoce 1: IRGA 421 (95); Muito Precoce 2: BRS Atalanta (100); BRS Ligeirinho (95); Precoce 1: BRS 6 "Chuí" (110); BRS Querência (110); EPAGRI 106 (106); IRGAP H9CL (110); Precoce 2: Avaxi CL (120); BR-IRGA 414 (115); BRS Firmeza (120); BRS Pampa (118); Guri Inta CL (120); Inov CL (120); IRGA 417 (115); IRGA 422 CL (120); IRGA 423 (120); IRGA 430 (120); Puitá Inta CL (120); Titan CL (120); Médio 1: Arize QM 1003 (125); Arize QM 1010 (135); BR-IRGA 409 (126); BR-IRGA 410 (123); BRS A701 CL (130); ); BRSCIRAD 302 (128); BRS Pelota (125); BRS Sinuelo CL (130); IRGA 426 (125); IRGA 428 CL (125); IRGA 429 (124); Lexus CL (128); Médio 2: BRS Bojuru (135); BRS Fronteira (135); BRS Pampeira (133); BRS 7 “Taim” (130); El Paso L. 144; IRGA 424 (132); IRGA 424 RI (133); IRGA 425 (132); IRGA 427 (136); IRGAP H7CL (135); SCS 115 CL (135) Tardio: EPAGRI 108 (142); EPAGRI 109 (142); SCS 112 (138); SCS 114 Andosan (140); SCS 116 Satoru (144); SCS 117 CL (144); SCS 118 Marques (144); SCS 121 CL (141); SCSBRS Tio Taka (141). Os números entre parênteses dizem respeito ao comprimento do ciclo indicado em Sosbai (2016).

Deve-se ressaltar que a data de um determinado estádio, de uma dada cultivar, é estimada para o subgrupo a que ela pertence e não para a cultivar propriamente dita. Entretanto, pelo fato de as cultivares terem sido enquadradas em sete subgrupos, a data de um estádio qualquer, de um determinado subgrupo, é muito próxima da que seria esperada para qualquer uma das cultivares pertencentes ao subgrupo.

\section{Estádio}

O passo seguinte consiste em selecionar um dos seis estádios de desenvolvimento da planta, segundo a escala de Counce et al. (2000), indicados a seguir: V4 - Planta com 4 folhas; R1 - Diferenciação da panícula; R2 - Emborrachamento; R4 - Início da floração; R8 - Início da maturação; R9 - Maturação completa.

A denominação dos estádios foi simplificada para favorecer o entendimento por parte do usuário, mas a denominação completa, de acordo com a escala de Counce et al. (2000), encontra-se na Tabela 1.

\section{Data de emergência}

Por último, deve-se indicar a data da emergência, disponível para o período de $1^{\circ}$ de setembro a 31 de dezembro. Considera-se a data de $50 \%$ de emergência, ou seja, quando cerca de $50 \%$ das plântulas da lavoura tenham emergido 
(plântulas com até $2 \mathrm{~cm}$ de altura). 0 programa foi desenvolvido considerando, fundamentalmente, o sistema de semeadura em solo seco (convencional, cultivo mínimo e plantio direto).

Os mapas disponíveis foram derivados da interpolação de um modelo do relevo do Estado do Rio Grande do Sul e do número de dias entre a emergência e cada um dos seis estádios, nas dezessete localidades em que esses parâmetros foram estimados pelo método de graus-dia. Essa interpolação foi obtida por meio do resultado de técnicas estatísticas de regressão múltipla que geraram equações para cada decêndio de data de emergência, desde o $1^{\circ}$ decêndio de setembro até o $2^{\circ}$ decêndio de dezembro, aplicadas então ao modelo espacial. Ao todo foram gerados 462 mapas representativos dos sete subgrupos de maturação, dos seis estádios e das onze datas de emergência.

\section{Resultados e discussão}

Após o preenchimento dos campos indicados anteriormente, o GD Arroz apresenta um conjunto de dados que podem ser considerados como informações de saída do programa e que estão indicadas como "Consulta por localidades" e "Consulta por mapas", como descrito a seguir.

\section{Consulta por localidades}

Para exemplificar, selecionaram-se as variáveis a seguir: Localidade: Alegrete; Subgrupo: 6-Médio 2 (131-135 dias); Cultivar: IRGA 424; Estádio: R1 - Diferenciação da panícula (DP); Data de emergência: 15/10. Após preencher os campos indicados, selecionou-se "Consulta por localidades" (Figura 1).

Em "Média (30 anos)", o campo "№ dias (E-R1)" indica que essa cultivar, da mesma forma que as demais cultivares do subgrupo médio 2, na média de trinta anos de dados diários de Tm, necessitou de 64 dias após a emergência para atingir o estádio de diferenciação da panícula. 0 campo "Data (R1)" indica que 64 dias após a emergência (15/10) corresponde ao dia 18/12. Isso indica a data média em que o estádio R1 ocorreu nesses trinta anos.

Em “Safra”, utilizando os dados e Tm da safra 2017/2018, o campo "№ dias (E-R1)" indica que essa cultivar, necessitou 63 dias após a emergência para atingir a diferenciação da panícula. Consequentemente, o campo "Data (R1)" indica que 63 dias após a emergência (15/10) corresponde ao dia 17/12, mostrando, portanto, que houve uma antecipação em 1 dia da data média de 30 anos, como indicado no campo "Desvio da média (dias)" (Figura 1). Isso indica que, no período compreendido entre 15/10 (emergência) até que se atinja a soma térmica necessária para a ocorrência do estádio R1, da safra em questão, a temperatura média do ar (Tm) foi mais alta do que a Tm da média histórica (30 anos), pois houve antecipação de um dia. Logo abaixo das informações de saída do programa (Figura 1) encontra-se um diagrama esquemático dos principais estádios de desenvolvimento da planta de arroz (escala de Counce et

Figura 1. Informações de saída do programa para a versão Web (Consulta por localidades), envolvendo o número médio de dias da emergência a diferenciação da panícula (E-R1), a data média de R1, na média de 30 anos e na safra, desvio da média (dias), e diagrama esquemático dos principais estádios de desenvolvimento da planta de arroz, com destaque para o estádio de R1 da escala de Counce et al. (2000).

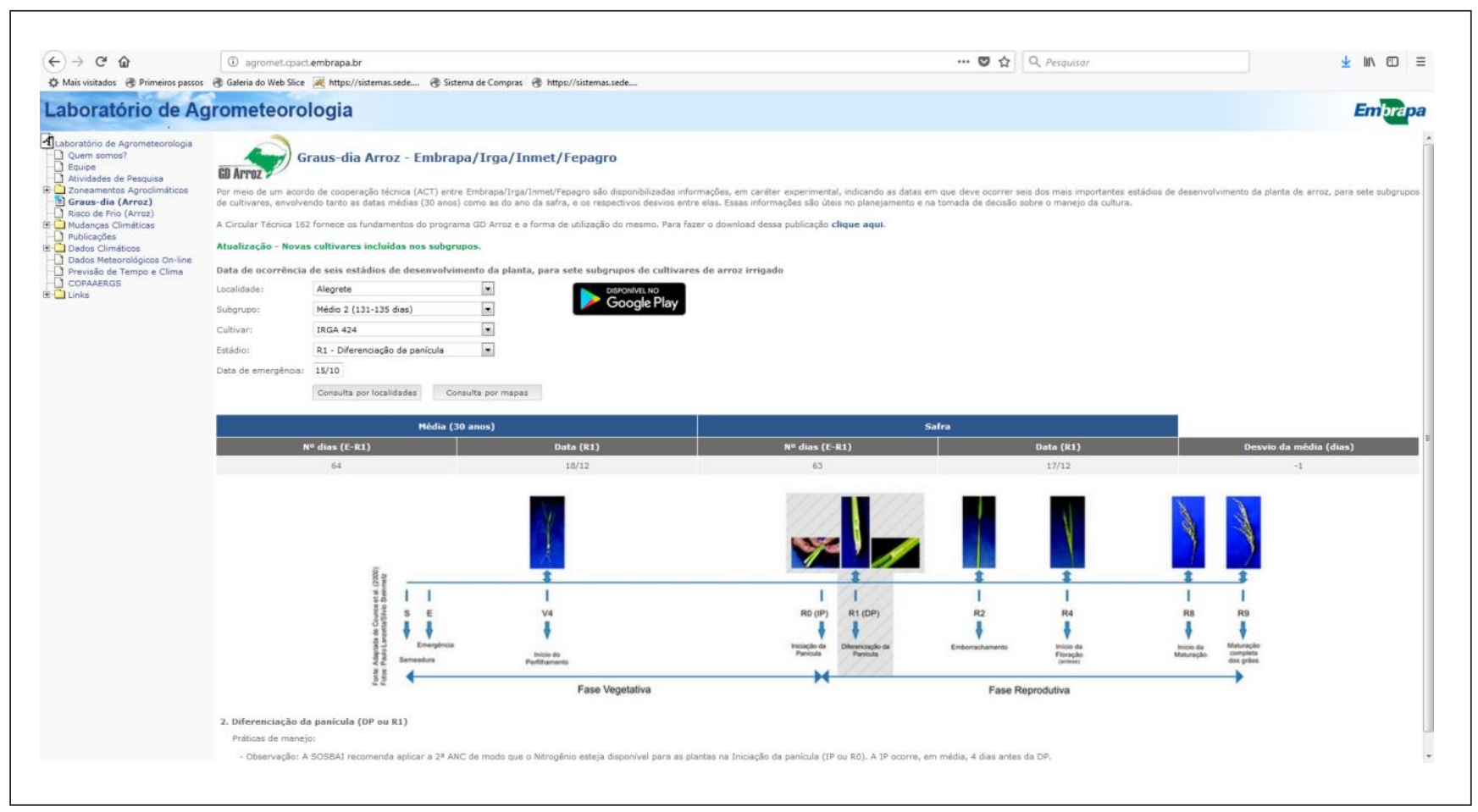


al., 2000), ressaltando o estádio que está sendo consultado, que é o R1, nesse exemplo.

\section{Consulta por mapas}

Outra possibilidade oferecida pelo programa é visualizar, na forma de mapas, a espacialização da informação gerada.

A informação disponibilizada nos mapas refere-se a classes de "№ dias (E-estádio)" para períodos de emergência de 10 dias, na média de 30 anos, considerando-se o valor intermediário do decêndio. Assim, o mapa do $1^{\circ}$ decêndio de outubro refere-se à emergência do dia 5 de outubro, o mapa do $2^{\circ}$ decêndio de outubro refere-se à emergência do dia 15 de outubro, e assim por diante.

Após preencher os campos indicados, seleciona-se "Consulta por mapas".

Essa consulta por mapas tem a finalidade de indicar ao usuário as informações geradas pelo programa, não apenas para a localidade selecionada, mas também para as localidades/municípios no seu entorno e, principalmente, para as que não dispõem de séries de dados meteorológicos como os das 17 localidades usadas neste trabalho.

A Figura 2 caracteriza a espacialização de classes de "№ dias (E-R1)" para as mesmas informações de entrada por "localidades" indicadas anteriormente, ou seja: Alegrete, subgrupo Médio 2, cultivar IRGA 424 (válido também para as demais cultivares que pertencem a esse subgrupo), com data de emergência em 15 de outubro (representada pelo mapa do segundo decêndio de outubro). Ela indica que a duração do subperíodo E-R1 é semelhante (classe de 6266 dias) em praticamente todo o município de Alegrete e também em todos os municípios que apresentam o mesmo tom de azul do referido município. Portanto, em todos esses municípios, a aplicação de qualquer prática de manejo associada a esse estádio poderia ser em data semelhante à de Alegrete.

o princípio de funcionamento do programa é o mesmo para cada um dos outros cinco estádios de desenvolvimento da planta de arroz.

A dificuldade em definir-se a data de $50 \%$ de emergência da lavoura, em função da desuniformidade de emergência das plântulas, causada pela escassez e/ou irregularidade na distribuição da chuva, por exemplo, também pode influenciar na acurácia da data de ocorrência de cada um dos seis estádios, estimados pelo método de graus-dia. Caso ocorram duas datas diferentes de emergência, de lavouras semeadas na mesma data, recomenda-se ao inserir os dados para estimar a data de cada um dos seis estádios, considerar-se como se fossem duas lavouras ao invés de fazer-se a média das duas datas de emergência.

\section{Uso do GD Arroz no manejo do arroz irrigado}

Na Figura 1, logo abaixo da ilustração sobre os estádios de desenvolvimento da planta, estão indicadas as principais práticas de manejo recomendadas pela Sociedade Sul-Brasileira de Arroz Irrigado (Sosbai, 2016) associadas a cada um dos seis estádios de desenvolvimento da planta. Serão indicados a seguir três exemplos de uso do GD Arroz no planejamento e na tomada de decisão sobre o manejo do arroz irrigado.

\section{Adubação nitrogenada em cobertura}

Considerando-se que a Sosbai (2016) recomenda que a segunda adubação nitrogenada em cobertura (ANC) deve ser realizada no estádio de iniciação da panícula (IP ou Ro) e que esse estádio é difícil de ser visualizado diretamente na planta, em condições de lavoura, pode-se usar, como referência, o estádio de diferenciação da panícula (DP ou R1), conhecido como "ponto de algodão", visível a olho nu, que ocorre, em média, quatro dias após a IP ou Ro (Carli, 2016). Portanto, na prática, se usaria a data estimada de DP (Safra) como referência, antecipando-se em quatro dias a aplicação da segunda ANC. Assim, no exemplo usado anteriormente, em que a data estimada de DP (Safra) ocorreu no dia 17/12, a aplicação da segunda ANC seria programada para o dia 13/12.

Embora a duração do período entre a emergência e a diferenciação da panícula seja afetada por fatores ambientais e do próprio manejo da cultura, como discutido por Steinmetz et al. (2010; 2013a), para fins práticos as estimativas fornecidas pelo GD Arroz podem ser muito úteis no planejamento da ANC bem como de outras práticas de manejo a serem efetuadas na lavoura.

A utilização do GD Arroz pode ser particularmente interessante quando existe a necessidade de programar a utilização de avião para realizar a ANC, que é uma prática rotineira nas médias e grandes lavouras de arroz irrigado no Rio Grande do Sul. Considerando-se que a partir da data de emergência da lavoura o estádio de DP ou R1 já pode ser previsto, utilizando-se a estimativa média (30 anos), o agendamento do avião também pode ser previsto. Com isso, além de garantir o avião para aplicar a ANC na época correta, poderia se ter outras vantagens resultantes desse agendamento antecipado. Pequenos ajustes, se necessários, poderiam ser feitos alguns dias antes da data prevista para a ANC utilizando-se as estimativas da data da DP do ano da safra.

\section{Elevação da lâmina de água e aplicação de fungicida}

As práticas de manejo como a elevação do nível da água para diminuir o efeito do frio e a aplicação de fungicida para controle de brusone são indicadas para serem feitas entre os estádios R2 (emborrachamento) e R4 (início da floração) (Sosbai, 2016). Do ponto de vista prático, o estádio R2 é relativamente fácil de ser identificado na 
Figura 2. Informações de saída do programa para as versões Web e Aplicativo para a plataforma Android (Consulta por mapas) indicando o mapeamento do número médio de dias da emergência a diferenciação da panícula (E-R1), na média de 30 anos, para o decêndio da data de emergência e para a cultivar (subgrupo) escolhidos, nas principais regiões produtoras de arroz irrigado do Rio Grande do Sul.

\section{GD Arroz}

\section{Graus-dia Arroz - Embrapa/Irga/Inmet/Fepagro}

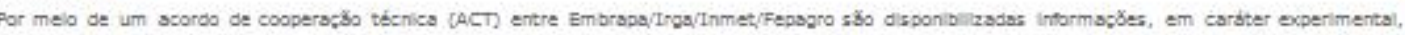
Indicando as datss em que deve ocorrer sels dos moss importantes estidios de desenvolimento da planta de arroz, para sete subgrupos de curtivares,

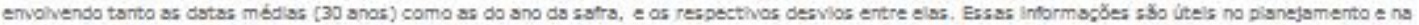
tomsta de decisbio sobre o maneja de cuitura.

A Circular Tésnica 152 fornece os fundamentos do programa GD Arroz e a forma de utlizaç̧o do mesmo. Para tazer o dawnilosd dessa pubilicazbo cllque aqui.

Atuallzaça - Novas cultivares incluidas nos subgrupos.

Data de ocorrencla de sels estádlos de desenvolvimento da planta, para sete subgrupos de culthvares de arroz lirrigado

$\begin{array}{ll}\text { Localldode: } & \text { Alegrete } \\ \text { Subgrupo: } & \text { Medlo 2 (131-135 diss) } \\ \text { Curtivar: } & \text { IRGA 424 } \\ \text { Estidlo: } & \text { R1 - Diterenclosibo do paniculo }\end{array}$

Dota de $15 / 10$

Consuta por localisades $\quad$ Consuts por mapss

Número de dlas da emergéncla ao estádlo R1

\begin{tabular}{|c|c|}
\hline 1-Alegrete & 10 - Santa Maris \\
\hline 2 -Boge & 11 - Santa Vitória do Paimar \\
\hline 3-Cachosirinhs & 12 - Santans do Livramento \\
\hline 4 - Copbía do LeŚ (Pelotas) & 13 - S30 Borfa \\
\hline 5 - Eldorado do Sul [Gualba] & $14-350$ o Gabriel \\
\hline 5- Encruzlinada da Sul & 15 - Toquari \\
\hline 7 - Maquiné (Osório) & 15 - Torres \\
\hline 8-Quarai & 17 - Urugualana \\
\hline 9 - Flo Grande & \\
\hline
\end{tabular}

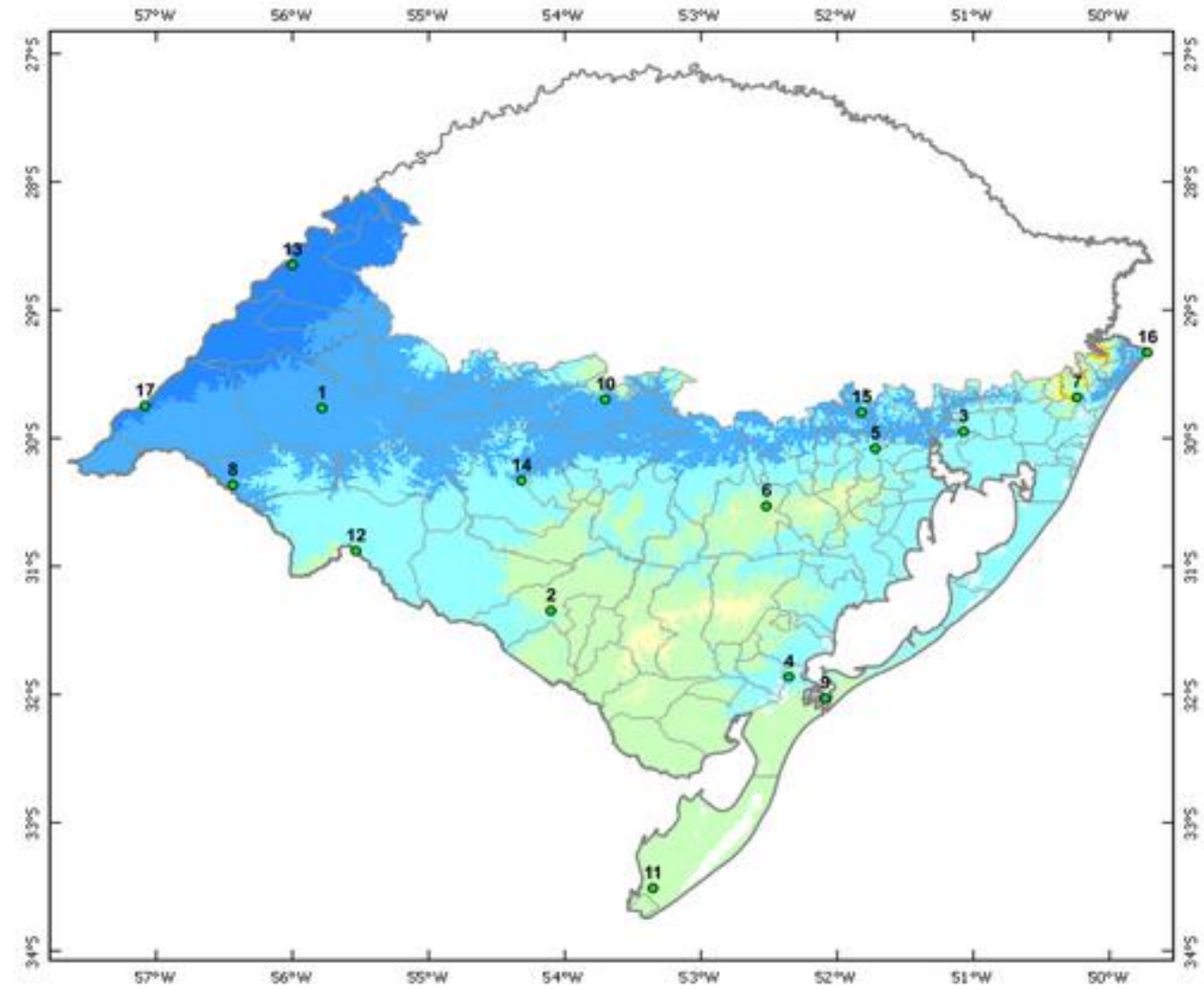


lavoura. Ele é caracterizado pela formação do colar na folha bandeira (Counce et al., 2000; Sosbai, 2016). Mesmo assim, os dados gerados pelo GD Arroz são úteis no planejamento dessas práticas de manejo.

Utilizando-se as mesmas informações do exemplo anterior, verifica-se que a duração do período da emergência (E) ao emborrachamento (R2) foi de 80 dias na "Média (30 anos)" e de 79 dias na "Safra" correspondendo, respectivamente, aos dias 3 e 2 de janeiro.

\section{Indicação da época de colheita}

O estádio R9 (maturação completa) também é relativamente fácil de ser identificado na lavoura. Ele é caracterizado pela maturidade completa dos grãos na panícula do colmo principal (Counce et al., 2000; Sosbai, 2016), também caracterizado como "ponto de colheita" pela Sosbai (2016). Embora o estádio R9 também seja facilmente identificado na lavoura, as estimativas do GD Arroz permitem auxiliar no planejamento da colheita. Esse planejamento pode ser mais abrangente envolvendo, por exemplo, o escalonamento da colheita por meio da definição do ciclo das cultivares a serem utilizadas, bem como a época de semeadura dessas cultivares em função da disponibilidade de colheitadeiras, capacidade de armazenamento na propriedade, do escoamento da safra para a indústria, de expectativa de preço do produto e de outras variáveis de interesse. Um exercício nesse sentido, envolvendo duas situações, é descrito a seguir.

O primeiro, assume que uma cultivar do subgrupo Médio 2, IRGA 424, por exemplo, foi semeada em três datas diferentes pressupondo que a emergência tenha ocorrido em 15 de setembro, 15 de outubro e 15 de novembro. As datas estimadas do estádio R9 (colheita), usando-se a "Média (30 anos)" seriam, respectivamente, em 5 de fevereiro, 20 de fevereiro e 14 de março. Com isso, haveria o escalonamento da colheita propiciando as vantagens indicadas anteriormente.

O segundo, assume que a emergência de três cultivares, com ciclos diferentes, tenha ocorrido em uma única data, 15 de outubro por exemplo. As cultivares seriam classificadas como de ciclos Precoce 2 (Guri Inta CL), Médio 2 (IRGA 424) e Tardio (SCS 121 CL). As datas estimadas do estádio R9 (colheita), usando-se a "Média (30 anos)" seriam, respectivamente, em 10 de fevereiro, 20 de fevereiro e 01 de março. Da mesma forma que no exemplo anterior, também a colheita seria escalonada.

Em ambos os exemplos, a partir da emergência das lavouras já poderia ter-se uma ideia aproximada de quando as colheitas seriam efetuadas, podendo usar essa informação para o planejamento da colheita, como indicado anteriormente. Os ajustes das datas de colheita seriam feitos alguns dias antes das datas previstas, usando-se as estimativas da "Safra" e pela verificação na própria lavoura.

Por problemas de ordem operacional, principalmente 8 o tempo de uso de computadores para executar o programa e o grande número de cultivares recomendadas pela Sosbai (2016), o GD Arroz estima a data de ocorrência dos seis estádios de desenvolvimento da planta para subgrupos de cultivares e não para as cultivares individualmente, como indicado anteriormente. o questionamento que se pode fazer é sobre o grau de acurácia das estimativas para subgrupos em relação as cultivares que pertencem a cada subgrupo. Resultados preliminares obtidos pelos autores (não publicados) indicam que, em 69\% dos dados analisados, considerando os dados médios para os seis estádios, as diferenças foram inferiores a três dias.

O monitoramento sobre o número de visitas ao GD Arroz, mantido pelo Núcleo de Tecnologia da Informação (NTI) da Embrapa Clima Temperado, indica que o total médio por ano foi de 9.600 visitas nos períodos de setembro/2015 a agosto/2016 e de setembro/2016 a agosto/2017. Cerca de $82 \%$ das visitas (7.870) concentraram-se nos meses de setembro a março, ou seja, no período da safra agrícola propriamente dita. No período de setembro a março, cerca de $52 \%$ das visitas ocorreram nos meses de dezembro e janeiro. Isso indica que o GD Arroz está sendo mais usado para programar a adubação nitrogenada em cobertura (ANC) havendo, portanto, a possibilidade de ampliação do seu uso para outras práticas de manejo como o fazem, por exemplo, os produtores de arroz irrigado em Arkansas (EUA) (Wilson Jr., 2015). Por outro lado, o aplicativo GD Arroz está classificado, de acordo com o "Google Play", na faixa de 500 ou mais instalações.

Acredita-se que a introdução de algumas melhorias no GD Arroz pode contribuir para aumentar o número de visitas. Dentre essas, destaca-se a possibilidade de consulta de qualquer município produtor de arroz e não apenas daqueles 17 disponíveis atualmente.

Em relação ao aplicativo, uma das opções seria disponibilizá-lo também para a plataforma iOS. Outra possibilidade seria implementar um recurso que permitisse o uso dessa ferramenta mesmo em locais (lavouras) sem acesso à internet e/ou telefonia móvel disponibilizando-a, por exemplo, no modo "offline" para consulta às estimativas "médias" baseadas nos dados de 30 anos de Tm. Nesse caso, a consulta às informações da "safra" seria feita em ambientes com acesso à internet e/ou telefonia móvel.

Além dessas melhorias, faz-se necessário aumentar a divulgação e o esclarecimento sobre a utilização do GD Arroz para que um maior número de produtores possam utilizá-lo.

Considerando-se que a data de ocorrência de cada um dos seis estádios pode ser influenciada por outros fatores, como indicado em Steinmetz et al. (2013a), recomenda-se que os usuários, ou os produtores propriamente ditos, utilizem as informações geradas pelo GD Arroz como uma ferramenta complementar, e não única, para o planejamento 
e a tomada de decisão quanto ao momento de efetuar as práticas de manejo indicadas no programa.

\section{Conclusão}

O GD Arroz (disponível nas versões Web e Aplicativo para a plataforma Android) é uma ferramenta que pode auxiliar o produtor a realizar as práticas de manejo nas épocas mais apropriadas por estimar a data de ocorrência de seis estádios de desenvolvimento da planta associados a essas práticas;

\section{Agradecimentos}

Os autores agradecem às instituições e pessoas envolł vidas nas diferentes etapas de desenvolvimento do programa GD Arroz. Cabe menção à Embrapa Clima Temperado, Embrapa Informática Agropecuária, Embrapa Pecuária Sul, Instituto Rio Grandense do Arroz (IRGA), Instituto Nacional de Meteorologia (INMET/8 ${ }^{\circ}$ DISME) e a extinta Fundação Estadual de Pesquisa Agropecuária (Fepagro)/atual Departamento de Diagnóstico e Pesquisa Agropecuária (DDPA), da Secretaria Estadual da Agricultura, Pecuária e Irrigação (SEAPI). Nossos agradecimentos são dirigidos, especialmente, aos pesquisadores, analistas, técnicos e assistentes de pesquisa, extensionistas rurais, estagiários e produtores rurais que contribuiram nas diferentes fases do desenvolvimento do programa GD Arroz.

\section{Referências}

BERGAMASCHI, H. Temperatura do ar. In: BERGAMASCHI, H.; BERGONCI, J. I. (Ed.). As plantas e o clima: princípios e aplicações. Guaíba, RS: Agrolivros, 2017. Cap. 6, p. 137-185.

CONAB. Companhia Nacional de Abastecimento. Acompanhamento da safra brasileira. Grãos. Safra 2017/2018. Sétimo levantamento. Abril 2018. Disponível em: <https://www.conab.gov.br/index.php/info-agro/ safras/graos>. Acesso em: 7 mai. 2018.

COUNCE, P. A.; KEISLING, T. C.; MITCHELL, A. J. A uniform, objective, and adaptive system for expressing rice development. Crop Science, Madison, v. 40, n. 2, p. 436-443, Mar./Apr. 2000.

CARLI, C. D.; STEINMETZ, S.; STRECK, N. A.; MARCHESAN, E.; SILVA, M. R. da. Número de dias e de graus-dia entre a iniciação e a diferenciação da panícula de cultivares de arroz irrigado. Ciência Rural, Santa Maria, v. 46, n. 3, p. 428-433, mar., 2016.

INFELD, J.A.; SILVA, J.B. da; ASSIS, F.N. de. Temperatura-base e grausdia durante o período vegetativo de três grupos de cultivares de arroz irrigado. Revista Brasileira de Agrometeorologia, Santa Maria, v.6, n.2, p.187-191, 1998.

SLATON, N.; HELMS, S.; WELLS, B. DD50 computerizedrice management program. In: HELMS, R.S. (Ed.). Rice production handbook. Little Rock, AR: University of Arkansas, 1996. p. 24-27. (Miscellany Publication, 192). SOCIEDADE SUL-BRASILEIRA DE ARROZ IRRIGADO (SOSBAI). Reunião Técnica da Cultura do Arroz Irrigado (31.: 2016: Bento Gonçalves, RS). Arroz irrigado: Recomendações técnicas da pesquisa para o Sul do Brasil. Pelotas: SOSBAI, 2016. 200p.
STANSEL, J.W. The rice plant - its development and yield. In: SIX DECADES OF RICE RESEARCH IN TEXAS. Beaumont: Texas Agricultural Experiment Station, 1975. p. 9-21.

STEINMETZ, S.; FAGUNDES, P. R. R.; MAGALHÃES JÚNIOR, A. M. de; SCIVITTARO, W. B.; DEIBLER, A. N.; ULGUIM, A. da R.; NOBRE, F. L. de L.; PINTANEL, J. B. A.; OLIVEIRA, J. G.; SCHNEIDER, A. B. Soma térmica e número de dias para atingir os principais estádios de desenvolvimento de $\mathbf{1 6}$ cultivares de arroz irrigado. Pelotas: Embrapa Clima Temperado, 2009. 31 p. (Embrapa Clima Temperado. Boletim de Pesquisa e Desenvolvimento, 89).

STEINMETZ, S.; MAGALHÃES JÚNIOR, A.M.; FAGUNDES, P.R.R.; SCIVITTARO, W.B.; ALMEIDA, I.R.; REISSER JÚNIOR, I.; DEIBLER, A.N.; MATZENAUER, R.; RADIN, B.; PRESTES, S.D.; SILVA, M.F. Uso de grausdia para estimar a data de diferenciação da panícula (DP) de seis subgrupos de cultivares de arroz irrigado visando à adubação nitrogenada em cobertura no Rio Grande do Sul. Pelotas: Embrapa Clima Temperado, 2010. 75p. (Embrapa Clima Temperado. Boletim de Pesquisa e Desenvolvimento, 121).

STEINMETZ, S.; PETRINI, J. A.; ALMEIDA, I. R. de; MAGALHÃES JÚNIOR, A. M. de; FAGUNDES, P. R. R.; DEIBLER, A. N.; RADIN, B.; PRESTES, S. D.; SILVA, M. F. ds; BERMUDEZ, D. A. Uso do método de graus-dia para estimar a data de ocorrência dos principais estádios de desenvolvimento de subgrupos de cultivares de arroz irrigado no Rio Grande do Sul. Pelotas: Embrapa Clima Temperado, 2013a. 108 p. Versão resumida (Embrapa Clima Temperado. Boletim de Pesquisa e Desenvolvimento, 205).

STEINMETZ, S.; PICADA, G. L. N.; GADEA, H. M.; KRÖEFF, R. M.; BORGES, V. M. P.; HANEMANN, L. C.; HERNANDES, G. C.; PEREIRA, C. P.; HERRMANN, D.; DEIBLER, A. N.; PILON, M.; PETRINI, J. A.; ALMEIDA, I. R. de; SILVA, M. F. da. Validação do método de graus-dia para estimar a data de diferenciação da panícula (DP) de cultivares de arroz irrigado no Rio Grande do Sul. Pelotas: Embrapa Clima Temperado, 2013b. 38 p. (Embrapa Clima Temperado. Boletim de Pesquisa e Desenvolvimento, 197).

STEINMETZ, S.; CUADRA, S. V.; PEREIRA, C. B.; SANTOS, E. L. dos; ALMEIDA, I. R. de. GD Arroz: programa baseado em graus-dia para estimar a data de diferenciação da panícula visando a adubação nitrogenada em cobertura. Pelotas: Embrapa Clima Temperado, 2014. 12p. (Embrapa Clima Temperado. Circular Técnica, 155).

STEINMETZ, S.; CUADRA,S. V.; PEREIRA, C. B.; SANTOS, E. L. dos; ALMEIDA, I. R. GD Arroz: programa baseado em graus-dia como suporte ao planejamento e à tomada de decisão no manejo do arroz irrigado. Pelotas:Embrapa Clima Temperado, 2015a. 8p. (Embrapa Clima Temperado. Circular Técnica, 162).

STEINMETZ, S.; FREITAS, T. S. de; KALSING, A.; TROJAN, S. da C.; LEONETTI, G. F. Validação do método de graus-dia para estimar a data de ocorrência dos principais estádios de desenvolvimento de cultivares de arroz irrigado. In: CONGRESSO BRASILEIRO DE ARROZ IRRIGADO, 9, 2015b, Pelotas. Anais...Pelotas: Embrapa Clima Temperado, 2015. Disponível em: <http://www.cbai2015.com.br/anais/index. php?secao=trabalhos>

STRECK, N. A.; BOSCO, L. C.; MICHELON, S.; ROSA, H. T.; WALTER, L. C.; PAULA, G. M. de; CAMERA, C.; LAGRO, I.; MARCOLIN, E. Avaliação da resposta ao fotoperíodo em genótipos de arroz irrigado. Bragantia, Campinas, v. 65, n. 4, p. 533-541, 2006.

VILLA NOVA, N. A.; PEDRO JÚNIOR, M. J.; PEREIRA, A. R.; OMETTO, J. C. Estimativa de graus-dia, acumulados acima de qualquer temperatura base, em função das temperaturas máxima e mínima. Caderno de Ciências da Terra, São Paulo, v. 30, n. 2, p. 1-8, 1972.

WILSON JR., C. E.; NORMAN, R. J.; SLATON, N. A.; BRANSON, J. W.; BOOTHE, D. L. DD50 computerized rice management program. Little Rock, AR: University of Arkansas: Division of Agriculture: Cooperative Extension Service [2015?]. (Agriculture and Natural Resources. Computer Technical Series). Disponível em: <https://www.uaex.edu/ publications/PDF/FSA-2124.pdf>. Acesso em: 15 jul. 2015. 


\title{
Principles of the software GD Arroz, for Web and Mobile devices, and its use in the irrigated rice management
}

\author{
Silvio Steinmetz ${ }^{1(*)}$, Santiago Vianna Cuadra ${ }^{1}$, Cristóvão Basilio Pereira ${ }^{1}$, Emerson Langie dos Santos ${ }^{1}$ and \\ Ivan Rodrigues de Almeida ${ }^{1}$ \\ ${ }^{1}$ Embrapa Clima Temperado, Rodovia BR 392, km 78, Caixa Postal 403, CEP 96.010-971 Pelotas, RS. E-mails: silvio.steinmetz@embrapa.br, \\ santiago.cuadra@embrapa.br; cristovao.pereira@embrapa.br, emerson.langie@embrapa.br and ivan.almeida@embrapa.br \\ ${ }^{(*)}$ Corresponding author.
}

\section{ARTICLE INFO}

Article history:

Received 22 May 2018

Accepted 20 December 2018

\section{Index terms:}

Oryza sativa L.

degree-day

phenology

crop management
ABSTRACT

The average grain yield of irrigated rice in the State of Rio Grande do Sul (RS), which accounts for $70 \%$ of Brazilian rice production, is relatively high ( $\left.7.6 \mathrm{t} \mathrm{ha}^{-1}\right)$. It is believed that this yield could be even greater if more farmers managed it according to the plant development stages, as indicated by the technical recommendations of the crop. The problem is that the occurrence of these stages, especially the panicle differentiation, is variable because it is affected by the temperature. Therefore, it is preferable to express these stages in days after emergence, but estimated by the degree-day (DD) method instead of the number of calendar days. For this reason the software "GD Arroz" was developed and validated, being available for Web and Mobile devices, the latter for the Android platform. This software allows to predict the date of occurrence of six development stages of the plant, for six subgroups of cultivars, in 17 localities of RS, using historical series (30 years) of daily average air temperature (Tm) as well as the Tm of the crop season. The objective of this article was to characterize the principles of the "GD Arroz" to predict dates of six plant development stages and how it can be used for timing some irrigated rice management practices in RS. The results allow us to conclude that the "GD Arroz" is a tool that can help the rice farmers for timing several management practices by predicting dates of six plant development stages.

\footnotetext{
CITATION

STEINMETZ, S.; CUADRA, S. V.; PEREIRA, C. B.; SANTOS, E. L.; ALMEIDA, I. R. Fundamentos do programa GD Arroz, versões Web e Aplicativo, e seu uso no manejo do arroz irrigado. Agrometeoros, Passo Fundo, v.26, n.1, p.1-10, 2018.
} 